DOI 10.37882/2223-2974.2020.09.13

\title{
ТЕНДЕНЦИИ ГЛОБАЛИЗАЦИИ В РАЗРЕЗЕ 2020 ГОДА
}

\section{TRENDS OF GLOBALIZATION IN THE CONTEXT OF 2020}

\section{E. Loginova}

Summary: The article considers the tendencies of globalization in the context of the crisis, considers the threats to globalization processes, the vulnerability of supply chains, presents an opinion on the development of a new wave of globalization.

Keywords: globalization, gig economy, world economy.
Логинова Екатерина Викторовна

К.э.н., Сибирский государственный университет науки и технологий имени академика М.Ф. Решетнёва, Красноярск lasfloresofdespiration@gmail.com

Аннотация: В статье рассмотрены тенденции глобализации в разрезе кризиса, рассмотрены угрозы для глобализационных процессов, уязвимость логистических цепочек, представлено мнение о развитии новой волны глобализации.

Ключевые слова: глобализация, gig экономика, мировая экономика.
I лобализация была трендом развития мировой экономики в текущее десятилетие. Массово развивались кросскультурные связи, транснациональные компании управляли издержками за счет региональных цен на ресурсы.

Новый коронавирус привел к хаосу в мировой экономике, закрыл предприятия, разрушил цепочки поставок и заставил миллионы людей потерять работу, работающих по трудовым соглашениям и для двух миллиардов неформальных работников в мире, которые составляют примерно 60 процентов мировой рабочей силы и часто зарабатывают менее 2 долларов в день. [1]

Эти рабочие, особенно в развивающихся странах, сталкиваются с надвигающейся экономической катастрофой. В отличие от работников формальной экономики, которые пользуются правовой и социальной защитой, неформальные работники зарабатывают себе на жизнь без страховки.

Это в основном женщины и в основном работающие не по найму, занятые в различных профессиях: уличная торговля, работа по дому, транспорт и сбор мусора. Некоторые из них также работают не по нормированному рабочему дню на фабриках, фермах и других официальных предприятиях, которые не предоставляют полные права или защиту всем своим сотрудникам.

Работники ГИГ-экономики и фрилансеры, которые заняты на исполнении контрактов и единичных проектах, поскольку гиг-экономика определяется как экономика краткосрочных контрактов и независимых работников. А поскольку во многих государстваx gig economy не признается со стороны правительства, то и поддержка работников в этой сфере во время кризиса не является приоритетной. Тем не менее, гиг экономика развивается, а многие консалтинговые и другие им подобные компании признают отсутствие падения эффективности в режиме удаленной работы, таким образом режим удаленной работы может стать существенным фактором развития новой волны глобализации и повышения ее эффективности.

Меры, принятые многими странами для борьбы с пандемией, в том числе меры по локализации, осуществляемые без значительной помощи тем, чья работа пострадала, угрожают источникам существования неформальных работников и еще больше толкают их на нищету, голод и бездомность [1].

В связи с кризисными явлениями возрастают протекционистские настроения со стороны государственных и региональных властей многих стран, а также кросс культурная напряжённость. Острые углы противоречий, сглаживаемые повышенным доходом от подобных коммуникации, в настоящее время становятся все более заметными.

Так, например Hyundai, пятый по величине автопроизводитель в мире, временно останавливал производство на своих заводах в Южной Корее в прошлом месяце из-за нехватки запчастей, произведенных в Китае [2].

Набирающий популярность регионализм в странах Европейского союза, протекционизм США, снижение туристической активности по всему миру - все это ведёт к изменениям в процессах глобализации.

Кризис 2020 года, связанный с пандемий, обозначил формирование совершенно нового уровня стресса для глобализации, создавая своего рода, тест на устойчивость.

Под ударом оказались слабые звенья логистических цепочек, системы здравоохранения и их зарубежные ис- 
точники снабжения. Кризис заставляет провести переоценку связей в мировой экономике.

Будет ли это изменение в методах хозяйствования или пересмотр направления всеобщего технологического развития в сторону роботизации на данном этапе оценить сложно. Но вместе с распространением карантинных мер распространилось влияние национальных экономик, а также выявилась глубокая взаимозависимость государства и частных компаний, в ходе которых все стороны находятся в процессе осознания и устранения уязвимостей.

Но урок нового коронавируса не в том, что глобализация провалилась. Урок заключается в том, что глобализация хрупка, несмотря на ее преимущества, или точнее из-за наличия этих преимуществ. В течение всего прошлого десятилетия отдельные фирмы прилагали усилия по устранению избыточных затрат на все виды ресурсов. Но эти усилия также сократили количество неиспользованных ресурсов - то, что экономисты называют «slack» - в глобальной экономике в целом. Из-за боязни неэффективности из бизнес процессов были убраны все так называемые излишками запасные варианты. В обычное время фирмы часто видят слаки (slack) как меру бездействия или даже растраты производственных мощностей. Но слишком малый запас запасных вариантов (а также излишков на складе, резервного персонала) делает глобальную систему более хрупкой во время кризиса, устраняя критические отказоустойчивости.

Отсутствие безотказных производственных альтернатив может привести к выходу из строя цепочек поставок, как это происходит в некоторых секторах медицины и здравоохранения в результате появления нового коронавируса. Производители жизненно важных предметов медицинского назначения были ошеломлены ростом мирового спроса, такие компании как Qiagen [8] и Roche не имели возможности ввести в производство дополнительные мощности, что привело к столкновению стран в борьбе за ресурсы [9]. Результатом стал сдвиг в динамике власти среди основных мировых экономик, причем те, которые хорошо подготовлены к борьбе с новым вирусом, либо накапливают ресурсы для себя, либо помогают тем, кто этого не делает, и в результате расширяют свое влияние на мировой арене.

Общепринятое мнение о глобализации заключается в том, что она создала процветающий международный рынок, позволяющий производителям создавать гибкие цепочки поставок, заменяя одного поставщика или компоненты (полуфабрикаты) на другого/других по мере необходимости. «Богатство народов» Адама Смита стало достоянием всего мира, поскольку предприятия воспользовались преимуществами глобального разделения труда. Международное разделение труда (между- народная специализация) стала причиной роста эффективности ряда национальных экономик, что, в свою очередь, привело к росту мировой экономики в целом.

В тоже время глобализация создала сложную систему взаимозависимости. Компании начали включаться глобальные цепочки поставок, создав запутанную систему производственных сетей, которые сплотили мировую экономику. Компоненты (полуфабрикаты) практически любого продукта теперь могут быть изготовлены в десятках стран. Такое стремление к специализации иногда затрудняло замену, особенно для необычных навыков или продуктов. И поскольку производство стало глобальным, страны также стали более взаимозависимыми, по причине того, что ни одна страна не может контролировать производство всех товаров и компонентов этих товаров (в том числе и субститутов), в которых нуждается ее экономика. Национальные экономики были включены в обширную глобальную сеть поставщиков.

Кризис 2020 года, вызванный волной закрытия границ и экономик, спровоцированных новым коронавирусом COVID-19, обнаруживает уязвимость этой глобализированной системы. Некоторые сектора экономики, особенно те, которые имеют высокую степень избыточности и в которых производство распределяется по нескольким странам, могут относительно хорошо пережить кризис. Другие могут оказаться на грани краха, если пандемия не позволит одному поставщику в одной стране произвести критический и широко используемый компонент. Например, автопроизводители в Западной Европе беспокоятся о нехватке мелкой электроники, потому что единственный производитель, MTA Advanced Automotive Solutions [2], был вынужден приостановить производство на одном из своих заводов в Италии.

На более ранних стадиях развития мировой экономики производители могли создавать запасы расходных материалов, чтобы защитить себя от влияния кризиса, похожего на этот. Но в эпоху глобализации многие компании взяли за основу критерий эффективности базирующееся на известном изречении генерального директора Apple Тима Кука о том, что наличие запасов это «основное зло» [3]. Вместо того, чтобы платить за содержание склада с запасами, которые им необходимы для производства их продуктов, эти компании полагаются на «своевременные» цепочки поставок, которые функционируют, исходя из принципа just-in-time (точно ко времени). Но в разгар глобальной пандемии своевременность может легко стать причиной простоя и опоздания поставок. Частично из-за проблем с цепочкой поставок, мировое производство ноутбуков в феврале упало на целых 50 процентов, а производство смартфонов может упасть на 12 процентов в следующем квартале. Оба вида продукта построены из компонентов, изготовленных специализированными азиатскими производителями [5]. 


\section{Оченка критических недостатков}

Производственные узкие места, подобные тем, которые существуют в производстве электроники, также затрудняют борьбу с новым коронавирусом. Во многих странах запасы критически важных медицинских препаратов, таких как реагенты, являются ключевым компонентом тест-наборов, которые используются лабораториями для обнаружения вирусной РНК, либо заканчиваются, либо их нет в наличии. В производстве необходимых реагентов доминируют две компании: голландская компания Qiagen (недавно приобретенная американским гигантом Thermo Fisher Scientific) [6] и лаборатории Roche, базирующаяся в Швейцарии. Оба не смогли справиться с необычайным ростом спроса на свою продукцию. Недостаток задержал производство тестовых наборов в Соединенных Штатах, которые вынуждены отставать от других стран, чтобы покупать необходимые им химикаты.

Принимая во внимание, что текущая администрация США использовала пандемию, чтобы отступить от глобальной интеграции и вернуть производственные мощности обратно, Китай использует кризис, чтобы продемонстрировать свою готовность к лидерству. Будучи первой страной, пораженной новым коронавирусом, Китай тяжело пострадал, но быстрее других мировых игроков адаптируется к новым вызовами. Это создает проблему для китайских производителей, многие из которых теперь снова работают и работают, но сталкивают- ся со слабым спросом в странах, находящихся в кризисе.

\section{Новая волна глобализашии}

Поскольку политики во всем мире пытаются бороться с новым коронавирусом и его последствиями, им придется столкнуться с тем фактом, что мировая экономика не работает так, как они думали. Глобализация требует все возрастающей специализации рабочей силы в разных странах, модель, которая создает исключительную эффективность, но также и чрезвычайную уязвимость. Такие шоки, как пандемия COVID-19, свидетельствуют об этих уязвимостях. Поставщики из одного источника или регионы мира, которые специализируются на одном конкретном продукте, могут создать неожиданную хрупкость в моменты кризиса, что приведет к разрушению цепочек поставок. В ближайшие месяцы будет выявлено еще много этих уязвимостей.

Таким образом можно предполагать, что новая волна глобализации будет включать в себя:

1. Создание альтернативных логистических цепочек и хабов

2. Перераспределение производства по развивающимся странам

3. Разработку методов и создание оптимальных резервов

4. Повышение темпов развития гиг-экономики

5. Снижение трудоемкости производств и оказания услуг в сторону большей автоматизации

\section{ЛИТЕРАТУРА}

1. Impact of the COVID-19 crisis on loss of jobs and hours among domestic workers [Электронный ресурc]. https://www.ilo.org/wcmsp5/groups/public/---ed_ protect/---protrav/---travail/documents/publication/wcms_747961.pdf (дата обращения: 09.07.20)

2. Virus Exposes Cracks in Carmakers' Chinese Supply Chains [Электронный ресурс] https://www.nytimes.com/2020/02/04/business/hyundai-south-koreacoronavirus.html (дата обращения: 09.07.20)

3. Will the Coronavirus End Globalization as We Know It [Электронный ресурс]. (дата обращения: 09.07.20) https://www.foreignaffairs.com/articles/2020-03-16/ will-coronavirus-end-globalization-we-know-it

4. МТА [Электронный ресурс]. http://www.mta.it/en (дата обращения: 09.07.20)

5. Apple's Tim Cook: The Genius Behind Steve Jobs (Fortune, 2008) | Fortune [Электронный pecypc]. https://www.google.com/amp/s/fortune.com/2008/11/24/ apple-the-genius-behind-steve/amp/ (дата обращения: 09.07.20)

6. China Smartphone Sales to Dramatically Fall in Q1 2020 Under the Shadow of nCoV (Novel Coronavirus) Epidemic [Электронный ресурс]. https://www. counterpointresearch.com/china-smartphone-sales-dramatically-fall-q1-2020-shadow-ncov-novel-coronavirus-epidemic/ (дата 0бращения: 09.07.20)

7. Gig economy [Электронный ресурс]. - https://mentamore.com/biznes/gig-economy-gignomika.html (дата обращения: 30.05.20)

8. Qiagen [Электронный ресурс]. https://www.qiagen.com/us (дата обращения: 09.07.20)

9. Roche - Doing now what patients need next [Электронный ресурc]. https://www.roche.com/ (дата обращения: 09.07.20)

10. ГИГ-экономика [Электронный ресурс]. - https://ucg.in.ua/gig-ekonomika-plyusyi-minusyi-realnost/ (дата обращения: 20.04.20)

11. Гигономика в фактах и цифрах [Электронный ресурc]. -https://rb.ru/story/gig-economy-facts/(дата обращения: 30.05.20)

12. Gig economy [Электронный ресурс]. https://edunet.pro/freelancers-tribune/gig-ehkonomika-chto-o-nej-sleduet-znat/ (дата 0бращения 31.05.2020)

13. РамблерІфинансы[Электронный ресурс]. https://finance.rambler.ru/economics/35664432-gig-ekonomika-kak-roboty-frilansery-i-internet-menyayutponyatie-raboty/ (дата обращения 01.06.2020)

14. СибАК [Электронный ресурс]. Логинова Е.В. Преимущетва ГИГ-экономики в условиях глобализации // Актуальные вопросы экономических наук и современного менеджмента: сб. ст. по матер. XXXIV междунар. науч.-практ. конф. № 5(27). - Новосибирск: СибАК, 2020. - С. 28-33. (дата обращения: 30.05.20)

(c) Логинова Екатерина Викторовна (lasfloresofdespiration@gmail.com).

Журнал «Современная наука: актуальные проблемы теории и практики» 